\title{
Evaluation of an FDA approved library against laboratory models of human intestinal nematode infections
}

\author{
Jennifer Keiser ${ }^{1,2^{*}}$, Gordana Panic ${ }^{1,2}$, Roberto Adelfio ${ }^{1,2}$, Noemi Cowan ${ }^{1,2}$, Mireille Vargas ${ }^{1,2}$ and Ivan Scandale ${ }^{3}$
}

\begin{abstract}
Background: Treatment options for infections with soil-transmitted helminths (STH) - Ascaris lumbricoides, Trichuris trichiura and the two hookworm species, Ancylostoma duodenale and Necator americanus - are limited despite their considerable global health burden. The aim of the present study was to test the activity of an openly available FDA library against laboratory models of human intestinal nematode infections.

Methods: All 1,600 drugs were first screened against Ancylostoma ceylanicum third-stage larvae (L3). Active compounds were scrutinized and toxic compounds, drugs indicated solely for topical use, and already well-studied anthelmintics were excluded. The remaining hit compounds were tested in parallel against Trichuris muris first-stage larvae (L1), Heligmosomoides polygyrus third-stage larvae (L3), and adult stages of the three species in vitro. In vivo studies were performed in the H. polygyrus and T. muris mice models.

Results: Fifty-four of the 1,600 compounds tested revealed an activity of $>60 \%$ against $A$. ceylanicum $\mathrm{L} 3$ (hit rate of $3.4 \%$ ), following incubation at $200 \mu \mathrm{M}$ for $72 \mathrm{~h}$. Twelve compounds progressed into further screens. Adult $A$. ceylanicum were the least affected $(1 / 12$ compounds active at $50 \mu \mathrm{M})$, while eight of the 12 test compounds revealed activity against T. muris $\mathrm{L} 1(100 \mu \mathrm{M})$ and adults $(50 \mu \mathrm{M})$, and H. polygyrus $\mathrm{L} 3(200 \mu \mathrm{M})$. Trichlorfon was the only compound active against all stages of $A$. ceylanicum, H. polygyrus and T. muris. In addition, trichlorfon achieved high worm burden reductions of 80.1 and $98.9 \%$, following a single oral dose of $200 \mathrm{mg} / \mathrm{kg}$ in the T. muris and H. polygyrus mouse model, respectively.

Conclusion: Drug screening on the larval stages of intestinal parasitic nematodes is feasible using small libraries and important given the empty drug discovery and development pipeline for STH infections. Differences and commonalities in drug activities across the different STH species and stages were confirmed. Hits identified might serve as a starting point for drug discovery for STH.
\end{abstract}

Keywords: FDA library, Soil-transmitted helminthiasis, Drug sensitivity assay, Trichuris muris, Ancylostoma ceylanicum, Heligmosomoides polygyrus

\section{Background}

Infections with soil-transmitted helminths (STH) - Ascaris lumbricoides, Trichuris trichiura and the two hookworm species, Ancylostoma duodenale and Necator americanus are enormously prevalent and responsible for a main part of the global health burden associated with neglected tropical diseases. Approximately 1.45 billion people are

\footnotetext{
* Correspondence: jennifer.keiser@unibas.ch

${ }^{1}$ Department of Medical Parasitology and Infection Biology, Swiss Tropical and Public Health Institute, Basel, Switzerland

2University of Basel, Basel, Switzerland

Full list of author information is available at the end of the article
}

infected globally with at least one STH species [1]. In 2013, 4.0 million disability adjusted life years (DALYs) were attributed to intestinal nematode infections [2]. Symptoms include malnutrition, iron deficiency, anemia, intestinal obstruction, chronic dysentery, rectal prolapse, and poor weight gain [3]. To date, the most cost-effective public health strategy is to control morbidity by periodically administering anthelmintic drugs of mainly albendazole and mebendazole, on a large-scale. In 2014, 138.2 and 258 million preschool-aged and school-aged children, respectively, were treated with the benzimidazoles in 
endemic countries [4]. This number will increase considerably over the next years, since more than 800 million children require annual treatment with anthelmintic drugs [4]. Drug resistance is a serious concern in light of the enormous drug pressure. In addition, the spectrum of activity of the benzimidazoles is sub-optimal; albendazole and mebendazole have only low efficacy against the intestinal nematode species $T$. trichiura when administered at single doses [5]. It is therefore imperative that the drug discovery pipeline produces viable alternatives.

Drug discovery for most of the STH is truly neglected. For example, in 2014 as little as 678,299 and 171,197 USD were invested in drug discovery research for hookworm and T. trichiura infections, respectively (https:// gfinder.policycures.org/PublicSearchTool). To our knowledge there are no novel drug candidates for soil-transmitted helminthiasis in the drug development pipeline.

In order to contribute to research and development efforts for these neglected tropical diseases, a series of libraries were screened for activity against hookworm and/or whipworm in the framework of a Gates-funded project in collaboration with the Drugs for Neglected Disease initiative. Here we present our results with an openly available FDA library. All 1,600 drugs were first screened against the larval stages of $A$. ceylanicum. Active compounds were examined and toxic compounds, drugs indicated solely for topical use and already wellstudied anthelmintics were excluded. The remaining hit compounds were tested in parallel against adult $A$. ceylanicum and against T. muris $\mathrm{L} 1$ and Heligmosomoides polygyrus L3 and adults in vitro. In vivo studies were performed in the $H$. polygyrus and T. muris mice models.

\section{Methods}

\section{Animals}

Three-week-old male Syrian Golden hamsters were purchased from Charles River (Sulzfeld, Germany). Fourweek-old female NMRI mice and female C57BL/10ScSn OlaHsd mice (age 3 weeks) were purchased from Harlan Laboratories (Horst, The Netherlands and Blackthorn, United Kingdom, respectively). All animals were kept in macrolon cages under environmentally-controlled conditions (temperature: $25{ }^{\circ} \mathrm{C}$, humidity: $70 \%$, light/dark cycle $12 \mathrm{~h} / 12 \mathrm{~h}$ ) and had free access to water (municipal tap water supply) and rodent food. Rodents were allowed to acclimatize for one week before infection. The current study was approved by the local veterinary agency, based on Swiss cantonal and national regulations (permission no. 2070).

\section{Drugs}

The FDA Pharmakon compound library was purchased from MicroSource Discovery Systems, Inc. (USA). Compounds $(10 \mathrm{mM}$, dissolved in DMSO) were stored at
$-80{ }^{\circ} \mathrm{C}$ until use. Levamisole and ivermectin, used for the in vitro controls, were purchased from Fluka and SigmaAldrich, respectively (Buchs, Switzerland), dissolved at $10 \mathrm{mM}$ stock solutions in DMSO, and stored at $-20{ }^{\circ} \mathrm{C}$ until further use. For the in vivo studies, bitoscanate, chlorcyclizine $\mathrm{HCl}$, clemastine, dicyclomine $\mathrm{HCl}$, drofenine $\mathrm{HCl}$, ethopropazine $\mathrm{HCl}$, lansoprazole, metformin $\mathrm{HCl}$, morantel, natamycin, trichlorfon, and trimipramine maleate were purchased from Sigma-Aldrich.

\section{In vitro tests on $A$. ceylanicum $\mathrm{L} 3$}

A. ceylanicum larvae (L3) were obtained by filtering the feces of infected hamsters and cultivating the eggs for 9 days in the dark at $24{ }^{\circ} \mathrm{C}$. L3 were washed in penicillin and streptomycin-supplemented tap water and kept under refrigeration until used. For the drug assay, $40 \mathrm{~L} 3$ were placed in each well of a 96-well plate for each compound, in duplicate. Worms were incubated with $200 \mu \mathrm{M}$ of the test drug and culture medium, which was composed of $100 \mu \mathrm{l}$ HBSS medium (Hanks' Balanced Salt Solution Modified; GIBCO, Lucerne, Switzerland) supplemented with $25 \mu \mathrm{g} / \mathrm{ml}$ amphotericin $\mathrm{B}, 100 \mathrm{U} / \mathrm{ml}$ penicillin, and $100 \mu \mathrm{g} / \mathrm{ml}$ streptomycin (Sigma-Aldrich). Worms incubated with culture medium and $1 \%$ DMSO served as negative controls. Wells containing larvae, medium, and $200 \mu \mathrm{M}$ of levamisole served as positive controls. The plates were kept at room temperature and in the dark for up to $72 \mathrm{~h}$, after which the drug effect was evaluated. To do so, first the total number of L3 per well was determined. Then, $100 \mu \mathrm{l}$ of hot water $\left(\approx 80{ }^{\circ} \mathrm{C}\right)$ was added to each well and the larvae that responded to this stimulus (the moving L3) were counted. The proportion of larval death was determined. A cut-off of $60 \%$ was used to define activity, hence compounds achieving $>60 \%$ larval death progressed to further testing.

\section{In vitro tests on $A$. ceylanicum adult worms}

Hamsters were infected per os with 150 A. ceylanicum L3. Three weeks post-infection, hamsters were euthanized with $\mathrm{CO}_{2}$ and the worms were collected from the intestine. For each compound, three A. ceylanicum adults were placed in each well of a 24-well plate, using 2 wells per compound. Worms were incubated in the presence of $50 \mu \mathrm{M}$ of the drug to be tested, and culture medium, which was composed of HBSS medium supplemented with $10 \%$ Fetal Calf Serum (FCS) (Connectorate AG, Dietikon, Switzerland), $25 \mu \mathrm{g} / \mathrm{ml}$ amphotericin B, $100 \mathrm{U} / \mathrm{ml}$ penicillin, and $100 \mu \mathrm{g} / \mathrm{ml}$ streptomycin. Worms incubated in $1 \%$ DMSO in culture medium served as control. As a positive control, ivermectin was used at a concentration of $50 \mu \mathrm{M}$. Worms were kept in an incubator at $37{ }^{\circ} \mathrm{C}$ and $5 \%$ $\mathrm{CO}_{2}$ for up to $72 \mathrm{~h}$. Thereafter, the condition of the worms was microscopically evaluated using a viability scale from 3 (normal activity and no tegument alteration) to 0 (dead, completely granulated). 
In vitro tests on $T$. muris $\mathrm{L} 1$ worms

Female C57BL/10ScSnOlaHsd mice were infected per os with 200-250 T. muris eggs showing around 90-95\% embryonation (checked microscopically). After 7 weeks, T. muris eggs were collected from the feces of the infected mice by the flotation method using saturated $\mathrm{NaCl}$ solution in Milli-Q water. T. muris eggs were stored in Milli-Q water in the dark for 3 months at 23$25{ }^{\circ} \mathrm{C}$, until the eggs were embryonated. The hatching process to obtain $T$. muris L1 has been described elsewhere [6]. For the assay, $40 \mathrm{~L} 1$ larvae were placed in each well of a 96-well plate. Worms were incubated in the presence of $100 \mu \mathrm{l}$ RPMI 1640 medium with $12.5 \mu \mathrm{g} / \mathrm{ml}$ amphotericin B, $500 \mathrm{U} / \mathrm{ml}$ penicillin, $500 \mu \mathrm{g} / \mathrm{ml}$ streptomycin, and $100 \mu \mathrm{M}$ of the drug to be tested. Each drug was tested in duplicate. L1 larvae incubated with culture medium and $1 \%$ DMSO served as a negative control and larvae incubated with levamisole at a concentration of $100 \mu \mathrm{M}$ were included as a positive control. The assay was kept in an incubator at $37{ }^{\circ} \mathrm{C}$ and $5 \% \mathrm{CO}_{2}$ for $24 \mathrm{~h}$. At $24 \mathrm{~h}$, the total number of L1 larvae per well was counted. The larvae were then stimulated with $100 \mu \mathrm{l}$ hot water $\left(\approx 80^{\circ} \mathrm{C}\right)$ and the moving L1 larvae were counted.

\section{In vitro assay with $T$. muris adult worms}

Seven weeks post-infection of female C57BL/10ScSn OlaHsd mice, T. muris adult worms were collected from the intestines. Three T. muris adult worms were placed in each well of a 24-well plate. Worms were incubated with culture medium and $50 \mu \mathrm{M}$ of the drug to be tested. Each compound was tested in duplicate. Trichuris muris adult worms incubated with $1 \%$ DMSO and culture medium served as control. As positive control, levamisole was used at a concentration of $50 \mu \mathrm{M}$. Worms were kept in an incubator at $37{ }^{\circ} \mathrm{C}$ and $5 \% \mathrm{CO}_{2}$ for $72 \mathrm{~h}$ and were subsequently microscopically evaluated using a viability scale from 3 (normal activity and no tegument alteration) to 0 (dead, completely granulated).

\section{Heligmosomoides polygyrus L3 in vitro studies}

Female NMRI mice were infected with $80 \mathrm{H}$. polygyrus L3 per os. $H$. polygyrus eggs were obtained from infected feces. The eggs were then placed on agar and, after 9 days in the dark at $24{ }^{\circ} \mathrm{C}$, the L3 larvae hatched. For the drug assay, 40 L3 larvae were placed in each well of a 96-well plate. Worms were incubated in the presence of $100 \mu \mathrm{l}$ RPMI 1640 medium, supplemented with $0.63 \mu \mathrm{g} / \mathrm{ml}$ amphotericin B, $500 \mathrm{U} / \mathrm{ml}$ penicillin, $500 \mu \mathrm{g} / \mathrm{ml}$ streptomycin, and $100 \mu \mathrm{M}$ of the drug to be tested. Each drug was tested in duplicate. Worms incubated with $1 \%$ DMSO and culture medium served as a negative control and wells containing larvae, medium and $100 \mu \mathrm{M}$ levamisole served as a positive control. The plates were kept at room temperature for up to $72 \mathrm{~h}$. To assess the effect of the compound, the total number of L3 larvae per well was counted, the larvae were stimulated with $100 \mu$ l hot water $\left(\approx 80{ }^{\circ} \mathrm{C}\right)$, and the moving L3 were counted.

\section{In vitro assay with $H$. polygyrus adults}

Female NMRI mice were infected with $80 \mathrm{H}$. polygyrus L3 per os. Two weeks post-infection, mice were dissected and three adult worms were placed in each well of a 24-well plate. Worms were incubated with culture medium and $50 \mu \mathrm{M}$ of the test drug. Each compound was tested in duplicate. Adult worms incubated with medium only and $50 \mu \mathrm{M}$ levamisole and ivermectin served as negative and positive control, respectively. Worms were kept in an incubator at $37{ }^{\circ} \mathrm{C}$ and $5 \% \mathrm{CO}_{2}$ for $72 \mathrm{~h}$ and, subsequently, were microscopically evaluated using a viability scale from 3 to 0 .

\section{Trichuris muris in vivo studies}

C57BL/10ScSnOlaHsd mice were infected with 200 embryonated $T$. muris eggs per os. The drinking water for the mice contained dexamethasone $(1 \mathrm{mg} / \mathrm{ml})$ in order to suppress their immune system to avoid rejection of the infection. At 42 days post-infection, the stool was collected and filtered to check for the presence of eggs. Infected mice were placed in individual cages. The compounds were administered by gavage at dosages of $10-400 \mathrm{mg} / \mathrm{kg}$ (guided by the $\mathrm{LD}_{50}$ values of the drugs). The dose volume was adjusted according to the mouse's body weight, which was assessed for each mouse directly prior to treatment. Four to six untreated mice served as controls. After $72 \mathrm{~h}$, the stool was collected from each cage to check and count the dead worms released through the stool. Six days post-treatment, animals were killed by the $\mathrm{CO}_{2}$ method and the gastrointestinal tract was collected. The intestine was dissected and adult worms were collected and counted.

\section{Heligmosomoides polygyrus in vivo studies}

NMRI mice were infected with $80 \mathrm{H}$. polygyrus L3 per os. Fourteen days post-infection, mice were treated orally with the test drugs at dosages of $10-400 \mathrm{mg} / \mathrm{kg}$. Four to six untreated mice served as controls. Ten days posttreatment, animals were killed by the $\mathrm{CO}_{2}$ method, and the gastrointestinal tract was collected. The intestine was dissected and adult worms were collected and counted.

\section{Statistics}

For the in vitro drug sensitivity assays, all viability scores/ larval survival counts were averaged across replicates and normalized to the average viability scores/larval survival counts of the control wells (Microsoft Office Excel 2010) using the following formula: Drug effect (\%) =100 \% [100 \% * (No. of live larvae alive/Total No. of larvae) drug/ (No. of live larvae/Total No. of larvae) control]. To 
calculate the drug effect in in vivo studies, the worm burden (WB) of treated animals was calculated and compared with the worm burden of control mice, which were infected simultaneously but were not treated. The worm burden reduction (WBR) was calculated as follows: WBR $(\%)=100 \%-(100 \% *$ WB treatment/WB control). The worm expulsion rates were calculated as follows: $(\mathrm{c} / \mathrm{d}) \times$ 100 , where $\mathrm{c}$ is the total number of expelled worms in a treated group and $\mathrm{d}$ is the total worm count (expelled worms as well as worms present in the gut counted following dissection) of the same group. The Kruskal-Wallis test (Statsdirect, statistical software version 2.8.0) was used to determine statistical significance of WBRs at a level of 0.05 .

\section{Results}

\section{In vitro studies}

The study flow is presented in Fig. 1. From 1,600 compounds tested, 54 compounds revealed an activity of $>60 \%$ against A. ceylanicum L3 (hit rate of $3.4 \%$ ), following incubation at $200 \mu \mathrm{M}$ for $72 \mathrm{~h}$. Twenty of these compounds killed all L3. Results are summarized in Table 1. The activities of the standard drugs, levamisole and ivermectin, (also included in the library) are presented as reference. Both drugs resulted in death of all $A$. ceylanicum L3.
Of the 54 compounds, 12 compounds have a topical indication and 19 drugs are toxic or are associated with severe adverse events. Twelve drugs (including levamisole and ivermectin) are well-known anthelmintics and, with exception of bitoscanate and morantel (for which little information on the efficacy against these parasites is available), were therefore not considered for further testing in the framework of this work. One drug, ftaxilide was not commercially available. Hence, 12 compounds progressed into further screens. Against adult A. ceylanicum, only trichlorfon resulted in death of the worms, while the remaining 11 compounds revealed low activity $(<60 \%$ activity). Eight of the 12 compounds affected $H$. polygyrus L3, with an activity of $>75 \%$. Adult $H$. polygyrus showed slightly higher sensitivity to the drugs as compared to adult A. ceylanicum, with dicyclomine $\mathrm{HCl}$ and ethopropazine $\mathrm{HCl}$ resulting in death of all worms, and trichlorfon and morantel revealing an activity of 79 and $80 \%$, respectively.

Against T. muris L1, nine of the 12 test compounds showed an activity ranging from $78-100 \%$, at a concentration of $100 \mu \mathrm{M}$ after $24 \mathrm{~h}$ of incubation. Six of these compounds caused death of all worms. The parallel tests on adult $T$. muris yielded nine compounds with high activity (75-100 \%) against T. muris adults, of which five compounds were lethal. There was a good correlation between larval and adult activity: two compounds were

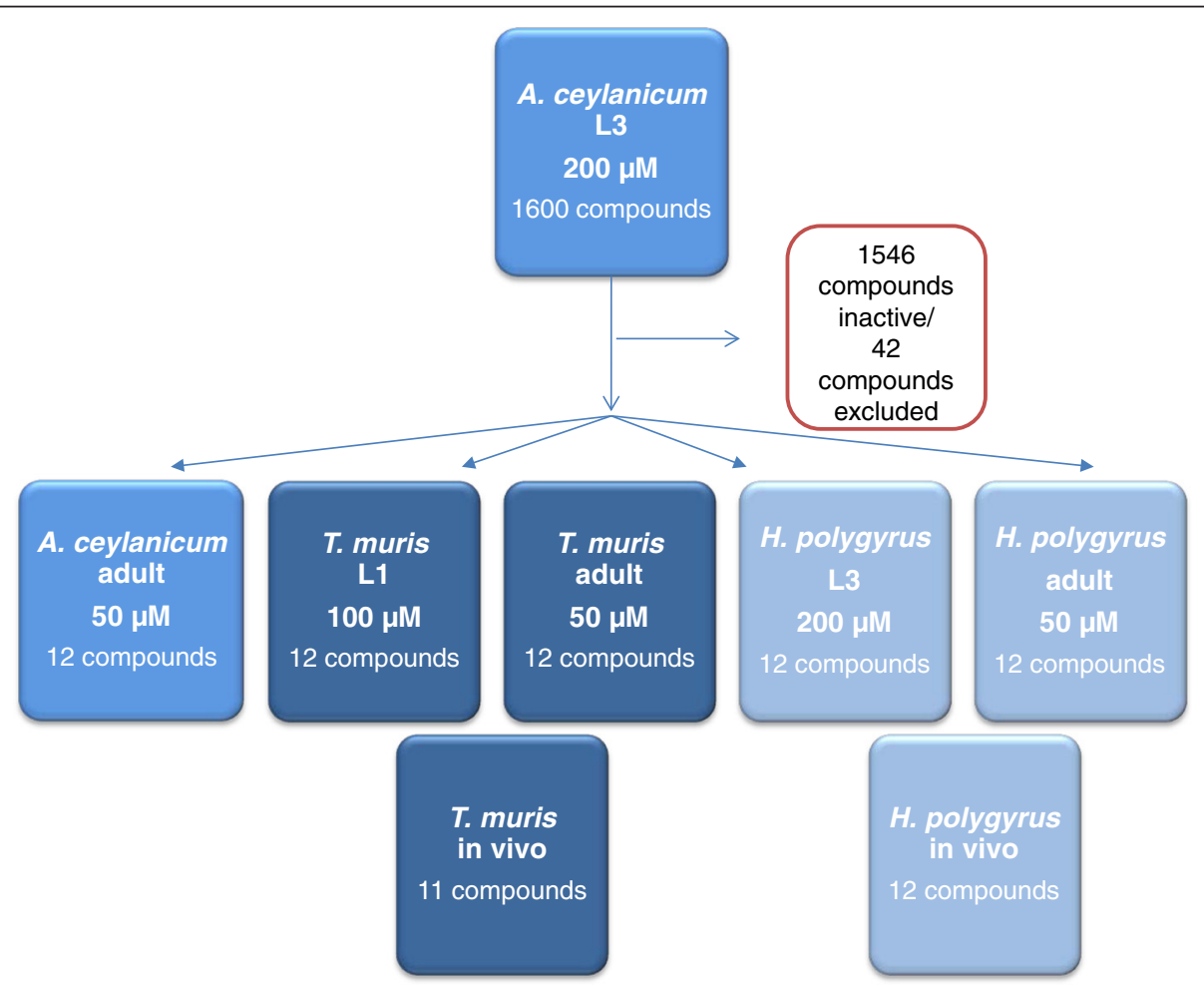

Fig. 1 Screening flow applied testing a library of 1600 FDA approved compounds against A. ceylanicum, T. muris and H. polygyrus 
Table 1 In vitro activity profile of 56 FDA compounds (including 2 reference compounds) against A. ceylanicum and T. muris adult and larval stages

\begin{tabular}{|c|c|c|c|c|c|c|}
\hline \multirow[t]{2}{*}{ Compound } & \multicolumn{6}{|l|}{ Drug effect (\%) } \\
\hline & $\begin{array}{l}\text { A. ceylanicum L3 } \\
200 \mu \mathrm{M}(72 \mathrm{~h})\end{array}$ & $\begin{array}{l}\text { H. polygyrus L3 } \\
200 \mu \mathrm{M}(72 \mathrm{~h})\end{array}$ & $\begin{array}{l}\text { T. muris L1 } \\
100 \mu \mathrm{M}(24 \mathrm{~h})\end{array}$ & $\begin{array}{l}\text { A. ceylanicum adult } \\
50 \mu \mathrm{M}(72 \mathrm{~h})\end{array}$ & $\begin{array}{l}\text { H. polyygrus adult } \\
50 \mu \mathrm{M}(72 \mathrm{~h})\end{array}$ & $\begin{array}{l}\text { T. muris adult } \\
50 \mu \mathrm{M}(72 \mathrm{~h})\end{array}$ \\
\hline Levamisole & 100 & 100 & 100 & 0 & 56 & 100 \\
\hline Ivermectin & 100 & 93 & 0 & 100 & 41 & 0 \\
\hline Abamectin & 100 & \multicolumn{5}{|l|}{ ND, anthelmintic } \\
\hline Amitriptyline $\mathrm{HCl}$ & 91 & \multicolumn{5}{|l|}{ ND, toxic } \\
\hline Apomorphine $\mathrm{HCl}$ & 72 & \multicolumn{5}{|l|}{ ND, toxic } \\
\hline Bifonazole & 67 & \multicolumn{5}{|c|}{ ND, topical application } \\
\hline Bitoscanate & 100 & 20 & 100 & 28 & 34 & 100 \\
\hline Carbachol & 89 & \multicolumn{5}{|c|}{ ND, topical application } \\
\hline Chlorambucil & 95 & \multicolumn{5}{|l|}{ ND, toxic } \\
\hline Chlorcyclizine $\mathrm{HCl}$ & 78 & 77 & 78 & 23 & 30 & 31 \\
\hline Chlorhexidine dihydrochloride & 61 & \multicolumn{5}{|c|}{ ND, topical application } \\
\hline Chloroxylenol & 100 & \multicolumn{5}{|c|}{ ND, topical application } \\
\hline Chlorpromazine & 100 & \multicolumn{5}{|l|}{ ND, toxic } \\
\hline Chlorprothixene $\mathrm{HCl}$ & 100 & \multicolumn{5}{|l|}{ ND, toxic } \\
\hline Chlorpyrifos & 97 & \multicolumn{5}{|l|}{ ND, toxic } \\
\hline Cisplatin & 87 & \multicolumn{5}{|l|}{$N D$, toxic } \\
\hline Clemastine fumarate & 76 & 91 & 2 & 47 & 30 & 100 \\
\hline Clomiphene citrate & 80 & \multicolumn{5}{|l|}{ ND, toxic } \\
\hline Coumophos & 100 & \multicolumn{5}{|l|}{ ND, toxic } \\
\hline Cyproheptadine $\mathrm{HCl}$ & 88 & \multicolumn{5}{|l|}{ ND, toxic } \\
\hline Dexlansoprazole & 88 & 35 & 1 & 47 & 17 & 55 \\
\hline Diatrizoic acid & 81 & \multicolumn{5}{|l|}{$N D$, toxic } \\
\hline Dibenzothiophene & 100 & \multicolumn{5}{|c|}{ ND, topical application } \\
\hline Dicyclomine $\mathrm{HCl}$ & 71 & 88 & 7 & 42 & 100 & 93 \\
\hline Dimpylate & 100 & \multicolumn{5}{|l|}{ ND, toxic } \\
\hline Doramectin & 100 & \multicolumn{5}{|l|}{ ND, anthelmintic } \\
\hline Doxepin $\mathrm{HCl}$ & 64 & \multicolumn{5}{|l|}{ ND, toxic } \\
\hline Drofenine $\mathrm{HCl}$ & 62 & 87 & 100 & 44 & 20 & 100 \\
\hline Dyclonine $\mathrm{HCl}$ & 100 & \multicolumn{5}{|l|}{ ND, topical } \\
\hline Eprinomectin & 100 & \multicolumn{5}{|l|}{ ND, anthelmintic } \\
\hline Ethopropazine $\mathrm{HCl}$ & 100 & 89 & 100 & 33 & 100 & 100 \\
\hline Fenbendazole & 66 & ND, anthelmintic & & & & \\
\hline Fenthion & 97 & ND, toxic & & & & \\
\hline Ftaxilide & 73 & ND, commercially & not available & & & \\
\hline Hexachlorophene & 100 & ND, topical & & & & \\
\hline Histamine dihydrochloride & 62 & ND, topical & & & & \\
\hline Mebendazole & 78 & ND, anthelmintic & & & & \\
\hline Metformin $\mathrm{HCl}$ & 100 & 11 & 100 & 50 & 27 & 75 \\
\hline Metitepine mesylate & 70 & ND, toxic & & & & \\
\hline Morantel citrate & 60 & 100 & 100 & 47 & 80 & 94 \\
\hline Moxidectin & 100 & ND, anthelmintic & & & & \\
\hline Natamycin & 95 & 14 & 100 & 53 & 10 & 61 \\
\hline
\end{tabular}


Table 1 In vitro activity profile of 56 FDA compounds (including 2 reference compounds) against A. ceylanicum and T. muris adult and larval stages (Continued)

\begin{tabular}{|c|c|c|c|c|c|c|}
\hline \multirow[t]{2}{*}{ Compound } & \multicolumn{6}{|l|}{ Drug effect (\%) } \\
\hline & $\begin{array}{l}\text { A. ceylanicum L3 } \\
200 \mu \mathrm{M}(72 \mathrm{~h})\end{array}$ & $\begin{array}{l}\text { H. polygyrus L3 } \\
200 \mu \mathrm{M}(72 \mathrm{~h})\end{array}$ & $\begin{array}{l}\text { T. muris L1 } \\
100 \mu \mathrm{M}(24 \mathrm{~h})\end{array}$ & $\begin{array}{l}\text { A. ceylanicum adult } \\
50 \mu \mathrm{M}(72 \mathrm{~h})\end{array}$ & $\begin{array}{l}\text { H. polyygrus adult } \\
50 \mu \mathrm{M}(72 \mathrm{~h})\end{array}$ & $\begin{array}{l}\text { T. muris adult } \\
50 \mu \mathrm{M}(72 \mathrm{~h})\end{array}$ \\
\hline Phenothiazine & 98 & ND, toxic & & & & \\
\hline Phenylmercuric acetate & 100 & ND, topical & & & & \\
\hline Pramoxine $\mathrm{HCl}$ & 100 & ND, topical & & & & \\
\hline Pyrantel pamoate & 91 & ND, anthelmintic & & & & \\
\hline Selamectin & 79 & ND, anthelmintic, & topical & & & \\
\hline Tetramizole $\mathrm{HCl}$ & 100 & ND, anthelmintic & & & & \\
\hline Thiabendazole & 93 & ND, anthelmintic & & & & \\
\hline Thonzonium bromide & 98 & ND, topical & & & & \\
\hline Trichlorfon & 100 & 89 & 100 & 100 & 79 & 100 \\
\hline Triclosan & 98 & ND, topical & & & & \\
\hline Triflupromazine $\mathrm{HCl}$ & 83 & ND, toxic & & & & \\
\hline Trimeprazine tartrate & 64 & ND, toxic & & & & \\
\hline Trimipramine maleate & 62 & 79 & 99 & 7 & 23 & 75 \\
\hline Zoxazolamine & 98 & ND, toxic & & & & \\
\hline
\end{tabular}

Abbreviation: ND Not done

active against adult T. muris, but not active against L1. Conversely, one compound showed no activity against adult $T$. muris despite being active against L1 (Table 1).

Trichlorfon was the only compound active against all stages of A. ceylanicum, $H$. polygyrus and T. muris.

\section{In vivo studies against $H$. polygyrus}

Identified hits from in vitro studies $(n=12)$ were further evaluated for in vivo proof of principle. To maximize chances of success, compounds were evaluated at high doses. Single administrations were favored to mimic dosing regimens used in mass drug administration programs for treatment of STH infections with the current standard of care.

Low activity was observed for chlorcyclizine $\mathrm{HCl}$, clemastine, dicyclomine $\mathrm{HCl}$, drofenine $\mathrm{HCl}$, ethopropazine $\mathrm{HCl}$, lansoprazole, metformin $\mathrm{HCl}$ and trimipramine maleate, with WBRs below $41 \%$. In mice treated with a single oral dose of $400 \mathrm{mg} / \mathrm{kg}$ natamycin, a WBR of $59.7 \%$ was observed. The highest activities were observed with bitoscanate and trichlorfon. Both dosages of bitoscanate $(100$ and $50 \mathrm{mg} / \mathrm{kg})$ resulted in significant WBRs of 100 and $98.8 \%$, respectively. A WBR (98.9\%) was achieved with a single oral dose of $200 \mathrm{mg} / \mathrm{kg}$ trichlorfon, curing three of four treated mice (Table 2). At $100 \mathrm{mg} / \mathrm{kg}$ trichlorfon, the calculated WBR was still significant (81.9\%).

\section{In vivo studies against $T$. muris}

Nine of the 11 compounds tested in vivo revealed a low activity against T. muris (WER $<7 \%$ and WBRs $<45 \%$ ).
Natamycin and morantel were not tolerated by the mice and five out of six mice died within $24 \mathrm{~h}$ post-treatment. Treatment of infected mice with bitoscanate achieved a WBR of $42 \%$, however, one of the mice died two days after treatment. The highest activity was observed with trichlorfon administered at $200 \mathrm{mg} / \mathrm{kg}$, which resulted in a WBR of $80 \%$ and a WER of $67 \%$. Halving the dose to $100 \mathrm{mg} / \mathrm{kg}$ resulted in a low WBR and WER (28.8 and $3.3 \%$, respectively) (Table 2 ).

\section{Discussion}

Drug repurposing is the key drug discovery strategy for human helminth infections, since anthelmintic drug discovery and development has languished [7]. Veterinary anthelmintics have obviously been the most attractive candidates for cross-over development for the treatment of human STH infections, since the regulatory standards for veterinary drugs are compatible with those for human drugs and a track-record of their use in animals exists [8]. Indeed, all of the few anthelmintics currently used for humans stem from veterinary medicine. In the present work, we applied a broader repurposing strategy, by evaluating 1,600 compounds from the FDA library, which contains approved drugs over a range of indications.

While a handful of studies employing target screening approaches have been conducted to identify new pharmacophores for the treatment of human STH infections [9], phenotypic screening of selected libraries on parasitic nematodes is basically non-existent. However, wholeorganism screens have several advantages over targetbased screening, since they are not constrained to single 
Table 2 In vivo studies against $H$. polygyrus and T. muris

\begin{tabular}{|c|c|c|c|c|c|c|c|c|}
\hline \multirow[t]{2}{*}{ Treatment } & \multirow{2}{*}{$\begin{array}{l}\text { Dose } \\
(\mathrm{mg} / \mathrm{kg})\end{array}$} & \multicolumn{4}{|l|}{ T. muris } & \multicolumn{3}{|l|}{ H. polygyrus } \\
\hline & & $\begin{array}{l}\text { No. of mice } \\
\text { cured/investigated }\end{array}$ & $\begin{array}{l}\text { Average } \\
\text { worm } \\
\text { number }\end{array}$ & $\begin{array}{l}\text { Worm } \\
\text { burden } \\
\text { reduction (\%) }\end{array}$ & $\begin{array}{l}\text { Worm } \\
\text { expulsion } \\
\text { rate (\%) }\end{array}$ & $\begin{array}{l}\text { No. of mice } \\
\text { cured/investigated }\end{array}$ & $\begin{array}{l}\text { Average } \\
\text { worm } \\
\text { number }\end{array}$ & $\begin{array}{l}\text { Worm } \\
\text { burden } \\
\text { reduction (\%) }\end{array}$ \\
\hline Control a & - & $0 / 6$ & 170.95 & - & - & - & - & - \\
\hline Control b & - & $0 / 4$ & 163.5 & - & - & - & - & - \\
\hline Control c & - & $0 / 4$ & 197.3 & - & - & - & - & - \\
\hline Control 1 & & & & & & $0 / 8$ & 61.3 & - \\
\hline Control 2 & & & & & & $0 / 8$ & 21.1 & \\
\hline Control 3 & & & & & & $0 / 12$ & 47.0 & \\
\hline Bitoscanate $e^{a, 3}$ & 100 & $0 / 3^{*}$ & 70.5 & 58.8 & 0.3 & $4 / 4$ & 0 & 100 \\
\hline Bitoscanate $^{2}$ & 50 & ND & - & - & - & $3 / 4$ & 0.25 & $98.8^{\natural}$ \\
\hline Chlorcyclizine $\mathrm{HCl}^{\mathrm{c}, 1}$ & 100 & $0 / 3$ & 115.0 & 41.7 & & $0 / 4$ & 39.5 & 35.6 \\
\hline Clemastine $^{b, 1}$ & 100 & $0 / 3$ & 130.7 & 20.1 & 2.5 & $0 / 4$ & 84.8 & 0 \\
\hline Dicyclomine $\mathrm{HCl}^{\mathrm{b}, 1}$ & 400 & $0 / 3$ & 245.5 & 0 & 39.1 & $0 / 4$ & 36.8 & 40.1 \\
\hline Drofenine $\mathrm{HCl}^{\mathrm{a}, 1}$ & 400 & $0 / 3$ & 267.6 & 0 & 3.1 & $0 / 4$ & 54.0 & 12.0 \\
\hline Ethoproprazine $\mathrm{HCl}^{\mathrm{b}, 1}$ & 200 & $0 / 3$ & 368.0 & 0 & 6.7 & $0 / 4$ & 45.5 & 25.8 \\
\hline Lansoprazole $^{1}$ & 400 & ND & - & - & - & $0 / 4$ & 43.0 & 29.9 \\
\hline Metformin $\mathrm{HCl}^{\mathrm{a}, 1}$ & 400 & $0 / 3$ & 140.6 & 17.7 & 0.6 & $0 / 4$ & 80.0 & 0 \\
\hline Morantel $^{c, 1}$ & 400 & $0 / 3^{* *}$ & 367.0 & 0 & 0 & $0 / 2^{* *}$ & & \\
\hline Natamycin $n^{a, 1}$ & 400 & $0 / 3^{* * *}$ & - & - & - & $2 / 4$ & 24.8 & 59.7 \\
\hline Trichlorfon ${ }^{c, 1}$ & 200 & $1 / 3$ & 34.0 & $80.1^{\natural}$ & 67.6 & $3 / 4$ & 0.5 & $98.9^{\natural}$ \\
\hline Trichlorfon ${ }^{a}$ & 100 & $0 / 3$ & 121.0 & 28.8 & 3.3 & $2 / 4$ & 8.5 & $81.9^{\natural}$ \\
\hline Trimipramine maleate ${ }^{c, 1}$ & 10 & $0 / 3$ & 113.3 & 42.6 & 0.1 & $0 / 4$ & 71.5 & 0 \\
\hline
\end{tabular}

Each ${ }^{*}$ indicates a mouse that died. Superscripts $1-3$ and a-c refer to the respective control groups ${ }^{\natural} P<0.05$

targets (which are not well characterized for helminths) [10]. Indeed, phenotypic approaches are more successful for small-molecule, first-in-class medicines than target based approaches [11]. High throughput assays with Caenorhabditis elegans often serve as a substitute for helminth phenotypic assays, because most assays for parasitic nematodes are laborious and low throughput. However, the correlation of activity against $C$. elegans to parasitic nematodes is not universal, with for example albendazole lacking activity against C. elegans [12].

We observed a hit rate of $3.4 \%$ against $A$. ceylanicum larvae, our primary screen, with hits ranging across a large spectrum of indications. For comparison, a hit rate of $\sim 7.6 \%$ was observed against S. mansoni schistosomula using the same library and also encompassing a wide range of compound indications [13]. As highlighted already for the S. mansoni screen [13], it was disappointing that many of the hits were unsuitable for further testing, notably due to documented toxicity or restriction to topical use. In addition, we excluded the common anthelmintics (e.g. mebendazole, pyrantel). Selected compounds were next tested against a panel of helminths, namely $A$. ceylanicum adults, $H$. polygyrus larvae and adults, as well as T. muris larvae and adults. A few observations are offered for discussion. First, A. ceylanicum L3 were selected for the primary screen since, compared to adult stages, their use offers many advantages, mainly in terms of ethical considerations, numbers available, and ease of provision [14]. However, larval stages may not always be equally as sensitive as the target parasite stage, the adult worms. For example, the veterinary anthelmintic, monepantel, lacks activity against $A$. ceylanicum L3, while it is active against the adult worm [15]. Hence, larval-based assays should be validated in terms of how larval sensitivity compares to the sensitivity of adult worms. Additional file 1: Table S1 summarizes the activity of all 54 A. ceylanicum $\mathrm{L} 3$ active drugs (including topical and toxic drugs) against adult $A$. ceylanicum, $T$. muris L1 and adult $T$. muris. In general, A. ceylanicum L3 were more sensitive in our assay to the test compounds than the adult stages. Increased sensitivities of larval forms over adult worms have been reported earlier including for $S$. mansoni schistosomula [16]. Though a high false positive rate (larval activity does not always translate to adult activity) is not optimally cost-effective, the risk of losing interesting compounds is minimal, and in any case, larval prescreens are still more cost-effective and more ethical than conducting the entire screen on adult stage worms. 
However, for T. muris this trend could not be confirmed (Additional file 1: Table S1). Adult T. muris were equally or even more sensitive than T. muris L1. Second, to our knowledge, we have for the first time compared the sensitivities of a small series of test drugs on larval and adult stages of the two hookworm species. The $H$. polygyrus model is widely used to study intestinal nematode infections, as it is easy to maintain in the laboratory and far more cost-effective than other laboratory hookworm rodent models [17]. The activity of compounds on $A$. ceylanicum L3 and $H$. polygyrus L3 was similar (only bitoscanate, dexlansoprazole, metformin and natamycin lacked activity against $H$. polygyrus L3). Similarly, the A. ceylanicum adult screen mirrored the adult $H$. polygyrus screen (except for dicyclomine $\mathrm{HCl}$ and ethopropazine, which showed activity against adult $H$. polygyrus). Hence, our results with a small panel of compounds support the use of $H$. polygyrus in the framework of anthelmintic drug discovery.

Only two compounds revealed activity in vivo, namely trichlorfon and bitoscanate. In addition, a moderate activity was observed with natamycin against $H$. polygyrus (two out of four mice cured), while the drug was not tolerated by $T$. muris infected mice. The low in vivo activity of many of the in vivo tested drugs might not be surprising, as bioavailable drugs from the FDA library of 1,600 approved drugs may not have the ideal profile for in vivo activity. Though there are exceptions (e.g. levamisole, ivermectin or albendazole) an ideal treatment for STH, particularly Trichuris spp. infections should be only poorly absorbed in order to target worms sitting in the gastrointestinal tract.

In vivo, trichlorfon revealed high activity against $H$. polygyrus and T. muris, while bitoscanate showed high activity against hookworm but was moderately active against $T$. muris. The organophosphate trichlorfon is mainly used as an ectoparasiticide [18]. However, it is also known for its antischistosomal properties [trichlorfon (metrifonate) was marketed for the treatment of $S$. haematobium prior to the advent of praziquantel] [19] and is applied for the control of intestinal nematode parasites of cattle and sheep. Trichlorfon is particularly used for nematodes that have developed resistance to other commonly-used anthelmintics [20]. In the past years, it was investigated for the treatment of Alzheimer's disease. Metrifonate, at various fixed and loading doses, was associated with significant cognitive improvement compared to placebo, where the slow-release break-down byproduct, 2,2-dichlorovinyl dimethyl phosphate (DDVP), is supposed to be the active component $[21,22]$. The broad activity of metrifonate is perhaps not surprising considering its mechanism of action; metrifonate is a cholinergic drug, acting as an irreversible non- selective acetylcholinesterase and butyrylcholinesterase inhibitor [21]. There is a history of active cholinergic anthelmintics including pyrantel and levamisole, which are both selective nAChR agonists, and ivermectin and moxidectin, which are modulators of glutamategated ion channels and nAChRs [23]. Emerging cholinergic anthelmintics, monepantel, tribendimidine and derquantel [24-26] have different nAChR subtype selectivities.

Bitoscanate was widely used prior to the advent of the benzimidazoles for the treatment of hookworm infections $[27,28]$. Despite its history of use, the literature is very scarce. Bitoscanate belongs to the broad isothiocyanate class of anthelmintic compounds, which occur widely in nature, particularly in plants of the mustard (Brassicacae) family [29]. In India, clinical trials with thousands of hookworm-infected patients were conducted, which revealed a high efficacy of the drug. Conflicting results were observed with regard to Trichuris spp.; while a good trichuricidal activity was observed in some settings [30], the high efficacy was not consistently seen [28]. Mild and transient adverse events were reported in the large number of studies done with bitoscanate [28]. However, in the US bitoscanate is listed as an extremely hazardous substance (http://nj.gov/health/ eoh/rtkweb/documents/fs/2172.pdf) which, when released in certain amounts in the environment, may be of immediate concern to the community. A related compound, amoscanate, was found to be effective against hookworm and schistosomes in humans, but was accompanied with severe liver toxicity in laboratory animals at high doses [31, 32]. However, another related compound, nitroscanate, is widely employed in veterinary medicine to treat roundworm, hookworm and tapeworms [33]. Currently, the isothiocyanates are researched for activity against intestinal bacteria and cancer [34, 35].

The same library was screened against $S$. mansoni larval stage and adult worms [13] with a very different set of hits. When compared, 15 (27.8\%) of the compounds identified as hits in this screen were also hits against S. mansoni newly-transformed schistosomula (NTS) (abamectin, chlorprothixene hydrochloride, clomiphene citrate, doramectin, eprinomectin, hexachlorophene, metformin hydrochloride, metitepine mesylate, moxidectin, natamycin, phenylmercuric acetate, selamectin, thonzonium bromide, trichlorfon and triflupromazine hydrochloride). The vast majority of these common hits were either toxic or for topical use only. However, it is also noted that the macrocyclic lactones, a group that acts on glutamate-gated ion channels [36], in general appear to be active against both $S$. mansoni and hookworm.

\section{Conclusions}

In conclusion, we tested the FDA library of 1,600 approved drugs using a screening cascade with the larval stages of 
the parasitic nematode, A. ceylanicum, as a primary model. Our work has demonstrated that drug screening on the larval stages of intestinal parasitic nematodes is feasible using small libraries and shows differences and commonalities in drug activities across the different STH species and stages. A moderate hit rate of $3.4 \%$ was observed with the FDA library of approved drugs, however many of the active drugs consisted of toxic compounds, compounds for topical use, or anthelmintics. Trichlorfon and bitoscanate were the only active compounds in in vivo studies; however both drugs have clear limitations. Nonetheless, structurally related pharmacophores might serve as a starting point for drug discovery for STH infections.

\section{Additional file}

Additional file 1: Table S1. In vitro activity profile of 56 FDA compounds against A. ceylanicum and T. muris larval and adult stages (including topical and toxic drugs). (DOCX $52 \mathrm{~kb}$ )

\section{Funding}

JK is grateful to the European Research Council (ERC-2013-CoG 614739A_HERO) for financial support. The funders had no role in design, in the collection, analysis, and interpretation of data; in the writing of the manuscript; and in the decision to submit the manuscript for publication.

\section{Availability of data and materials}

The datasets supporting the conclusion of this article are included within the article and its additional file.

\section{Authors' contributions}

RA and JK designed the studies. RA, MV and NC carried out the experiments. JK wrote the first draft of the manuscript. GP, NC and IS revised the manuscript. All authors read and approved the final version of the manuscript.

\section{Competing interests}

The authors declare that they have no competing interests.

\section{Consent for publication}

Not applicable.

\section{Ethics approva}

The current study was approved by the local veterinary agency based on Swiss cantonal and national regulations (permission no. 2070).

\section{Author details}

'Department of Medical Parasitology and Infection Biology, Swiss Tropical and Public Health Institute, Basel, Switzerland. ${ }^{2}$ University of Basel, Basel, Switzerland. ${ }^{3}$ Drugs for Neglected Disease initiative, Chemin Louis-Dunant 15, 1202 Genève, Switzerland.

Received: 3 May 2016 Accepted: 1 June 2016

Published online: 01 July 2016

\section{References}

1. Pullan RL, Brooker SJ. The global limits and population at risk of soiltransmitted helminth infections in 2010. Parasit Vectors. 2012;5:81.

2. Murray CJ, Barber RM, Foreman KJ, Abbasoglu Ozgoren A, Abd-Allah F, Abera SF, et al. Global, regional, and national disability-adjusted life years (DALYs) for 306 diseases and injuries and healthy life expectancy (HALE) for 188 countries, 1990-2013: quantifying the epidemiological transition. Lancet. 2015;386:2145-91.
3. Ojha SC, Jaide C, Jinawath N, Rotjanapan P, Baral P. Geohelminths: public health significance. J Infect Dev Ctries. 2014;8:5-16.

4. World Health Organisation. Soil-transmitted helminthiases: number of children treated in 2014. Wkly Epidemiol Rec. 2015;90:705-11.

5. Keiser J, Utzinger J. The drugs we have and the drugs we need against major helminth infections. Adv Parasitol. 2010;73:197-230.

6. Wimmersberger D, Tritten L, Keiser J. Development of an in vitro drug sensitivity assay for Trichuris muris first-stage larvae. Parasit Vectors. 2013;6:42

7. Panic G, Duthaler U, Speich B, Keiser J. Repurposing drugs for the treatment and control of helminth infections. Int J Parasitol Drugs Drug Resist. 2014:4:185-200.

8. de Hostos EL, Nguyen T. Anthelmintic drugs: tools and shortcuts for the long road from discovery to product. In: Parasitic Helminths: Wiley-VCH Verlag GmbH \& Co. KGaA; 2012: 217-232.

9. Cho Y, Vermeire JJ, Merkel JS, Leng L, Du X, Bucala R, et al. Drug repositioning and pharmacophore identification in the discovery of hookworm MIF inhibitors. Chem Biol. 2011:18:1089-101.

10. Paveley RA, Bickle QD. Automated imaging and other developments in whole-organism anthelmintic screening. Parasite Immunol. 2013;35:302-13.

11. Swinney DC, Anthony J. How were new medicines discovered? Nat Rev Drug Discov. 2011:10:507-19.

12. Keiser J. Is Caenorhabditis elegans the magic bullet for anthelminthic drug discovery? Trends Parasitol. 2015;31:455-6.

13. Panic G, Vargas M, Scandale I, Keiser J. Activity profile of an FDA-approved compound library against Schistosoma mansoni. PLoS Negl Trop Dis. 2015;9:e0003962.

14. Paveley RA, Mansour NR, Hallyburton I, Bleicher LS, Benn AE, Mikic I, et al. Whole organism high-content screening by label-free, image-based Bayesian classification for parasitic diseases. PLoS Negl Trop Dis. 2012;6:e1762.

15. Tritten $L$, Silbereisen A, Keiser J. In vitro and in vivo efficacy of monepantel (AAD 1566) against laboratory models of human intestinal nematode infections. PLoS Negl Trop Dis. 2011;5:e1457.

16. Ingram-Sieber K, Cowan N, Panic G, Vargas M, Mansour NR, Bickle QD, et al. Orally active antischistosomal early leads identified from the open access malaria box. PLoS Negl Trop Dis. 2014;8:e2610.

17. Harris NL, Pleass R, Behnke JM. Understanding the role of antibodies in murine infections with Heligmosomoides (polygyrus) bakeri: 35 years ago, now and 35 years ahead. Parasite Immunol. 2014:36:115-24.

18. Chang CC, Rahmawaty A, Chang ZW. Molecular and immunological responses of the giant freshwater prawn, Macrobrachium rosenbergii, to the organophosphorus insecticide, trichlorfon. Aquat Toxicol. 2013;130-131:18-26.

19. Utzinger J, Keiser J. Schistosomiasis and soil-transmitted helminthiasis: common drugs for treatment and control. Expert Opin Pharmacother. 2004;5:263-85.

20. Fiel C, Guzman M, Steffan P, Rodriguez E, Prieto O, Bhushan C. The efficacy of trichlorphon and naphthalophos against multiple anthelmintic-resistant nematodes of naturally infected sheep in Argentina. Parasitol Res. 2011;109 Suppl 1:S139-48

21. Schneider LS, Giacobini E. Metrifonate. A cholinesterase inhibitor for Alzheimer's disease therapy. CNS Drug Rev. 1999:5:13-26.

22. Lopez-Arrieta JM, Schneider L. Metrifonate for Alzheimer's disease. Cochrane Database Syst Rev. 2006;2:Cd003155.

23. Martin RJ, Puttachary S, Buxton SK, Verma S, Robertson AP. The Conqueror Worm: recent advances with cholinergic anthelmintics and techniques excite research for better therapeutic drugs. J Helminthol. 2015;89:387-97.

24. Kaminsky R, Ducray $P$, Jung M, Clover R, Rufener $L$, Bouvier J, et al. A new class of anthelmintics effective against drug-resistant nematodes. Nature. 2008;452:176-80.

25. Rufener L, Maser P, Roditi I, Kaminsky R. Haemonchus contortus acetylcholine receptors of the DEG-3 subfamily and their role in sensitivity to monepantel. PLoS Pathog. 2009;5:e1000380.

26. Buxton SK, Charvet CL, Neveu C, Cabaret J, Cortet J, Peineau N, et al. Investigation of acetylcholine receptor diversity in a nematode parasite leads to characterization of tribendimidine- and derquantel-sensitive nAChRs. PLoS Pathog. 2014;10:e1003870.

27. Harinasuta T, Bunnag D. Clinical field trial of bitoscanate in Necator americanus infection, South Thailand. Prog Drug Res. 1975;19:64-9.

28. Samuel MR. Clinical experience with bitoscanate. Prog Drug Res. 1975;19:96-107. 
29. Pedras MS, Zheng QA, Gadagi RS. The first naturally occurring aromatic isothiocyanates, rapalexins $\mathrm{A}$ and $\mathrm{B}$, are cruciferous phytoalexins.

Chem Commun (Camb). 2007:4:368-70.

30. Biagi F. Experience with bitoscanate in hookworm disease and trichuriasis in Mexico. Prog Drug Res. 1975: 23-27

31. Shapiro TA, Were JB, Talalay P, Bueding E, Rocco L, Danso K, et al. Clinical evaluation of amoscanate in healthy male volunteers. Am J Trop Med Hyg. 1986;35:945-53.

32. Doshi JC, Vaidya AB, Sen HG, Mankodi NA, Nair CN, Grewal RS. Clinical trials of a new anthelmintic, 4-isothiocyanato-4'-nitrodiphenylamine (C.9333-Go/ CGP 4540), for the cure of hookworm infection. Am J Trop Med Hyg. 1977;26:636-9

33. Craig TM, Mercer SH, Wade CG, Lynn RC. Efficacy of nitroscanate against naturally acquired infection with Ancylostoma caninum, Dipylidium caninum, and Trichuris vulpis in dogs. Am J Vet Res. 1991:52:574-5.

34. Nowicki D, Rodzik O, Herman-Antosiewicz A, Szalewska-Palasz A. Isothiocyanates as effective agents against enterohemorrhagic Escherichia coli: insight to the mode of action. Sci Rep. 2016;6:22263.

35. Wu X, Zhou QH, Xu K. Are isothiocyanates potential anti-cancer drugs? Acta Pharmacol Sin. 2009;30:501-12.

36. Cully DF, Vassilatis DK, Liu KK, Paress PS, Van der Ploeg LH, Schaeffer JM, Arena JP. Cloning of an avermectin-sensitive glutamate-gated chloride channel from Caenorhabditis elegans. Nature. 1994;371:707-11.

\section{Submit your next manuscript to BioMed Central} and we will help you at every step:

- We accept pre-submission inquiries

- Our selector tool helps you to find the most relevant journal

- We provide round the clock customer support

- Convenient online submission

- Thorough peer review

- Inclusion in PubMed and all major indexing services

- Maximum visibility for your research

Submit your manuscript at www.biomedcentral.com/submit

) Biomed Central 